\title{
CORRECTION
}

View Article Online

View Journal I View Issue
W) Check for updates

Cite this: J. Anal. At. Spectrom., 2020, 35, 1506

DOI: $10.1039 / d 0 j a 90044 c$

rsc.li/jaas

\section{Correction: Wavelet-based interference correction for laser-induced breakdown spectroscopy}

Y. M. Guo, ${ }^{a}$ L. M. Deng, ${ }^{a}$ X. Y. Yang, ${ }^{a}$ J. M. Li, ${ }^{a}$ K. H. Li, ${ }^{a}$ Z. H. Zhu, ${ }^{a}$ L. B. Guo, ${ }^{\text {ta }}$ X. Y. Li, ${ }^{a}$ Y. F. Lu ${ }^{b}$ and X. Y. Zeng ${ }^{a}$

Correction for 'Wavelet-based interference correction for laser-induced breakdown spectroscopy' by Y. M. Guo et al., J. Anal. At. Spectrom., 2017, 32, 2401-2406, 10.1039/C7JA00204A.

The authors regret the error in the affiliation of one of the authors, Yongfeng $\mathrm{Lu}$, in the original manuscript. The correct affiliation is: University of Nebraska-Lincoln (UNL) and not Wuhan National Laboratory for Optoelectronics (WNLO) at the Huazhong University of Science and Technology (HUST). The corrected list of authors and affiliations for this paper is as shown above.

The Royal Society of Chemistry apologises for these errors and any consequent inconvenience to authors and readers. 